\title{
A experiência de um processo de formação articulando humanização e apoio institucional no trabalho em saúde
}

\author{
Monica Maria Raphael da Roza(a) \\ Maria Elizabeth Barros de Barros ${ }^{(b)}$ \\ Carla Ribeiro Guedes(c) \\ Serafim Barbosa Santos Filho(d)
}

Roza MMR, Barros MEB, Guedes CR, Santos Filho SB. Experience of an educacion process linking humanization and institutional support within healthcare work. Interface (Botucatu). 2014; 18 Supl 1:1041-52.

This paper presents an education experience relating to humanization within the framework of institutional support. In this process, the following political-methodological guidelines were proposed: (i) to take the Brazilian Health System (SUS) network to be a concrete space for labor relations and production of subjectivities, thus leading to thinking of it in its 'autonomous capacity'; (ii) to include institutional support as a strategy for interspersing in the movements of this network, thus enhancing its state of autonomy; and (iii) to conceive of the education process as a strategy for placing the ways of working within this network under analysis, thus inducing or strengthening the potential for workers to act as institutional supporters. This is the end product that we indicate here in order to add extended objectives to this education activity. The course had a group strengthening function and fostered networks, but this is not a finished process, since it follows the course of life, with its intrinsic variations.

Keywords: Education experience. Humanization. Institutional support. Healthcare work.
O texto apresenta uma experiência de formação na Humanização com referenciais do apoio institucional. Na formação foram propostas diretrizes político-metodológicas: (i) tomar a rede do Sistema Único de Saúde (SUS) como o espaço concreto das relações de trabalho e produção de subjetividades, induzindo-se a pensála em sua 'capacidade autônoma' (ii) compreendendo o apoio institucional como estratégia de se entremear nos movimentos de tal rede, potencializando a sua condição de autonomia e (iii) concebendo o processo formativo como estratégia de colocar em análise os modos de trabalho nessa rede, induzindo ou fortalecendo o potencial dos trabalhadores para agirem como apoiadores institucionais. Este é o produto-efeito que aqui indicamos para agregar em si os objetivos ampliados dessa atividade formativa. O curso exerceu função de grupalidade, aqueceu redes, mas não é um processo finalizado, pois que acompanha a vida na variação que lhe é própria.

Palavras-chave: Experiência de formação. Humanização. Apoio institucional. Trabalho em saúde. (a) Departamento de Psicologia, Universidade Federal Fluminense (UFF) - Campus Universitário Rio das Ostras/IHS/UFF. Rua Recife, s/n, Jardim Bela Vista. Rio das Ostras RJ, Brasil. 28895-532. monica.roza@gmail.com

(b) Departamento de Psicologia, Universidade Federal do Espírito Santo (Ufes). Vitória, ES, Brasil. betebarros@uol.com.br

(c) Departamento de

Saúde e Sociedade, Instituto de Saúde Coletiva, UFF. Niterói, RJ Brasil.carla.rguedes@ gmail.com

(d) Departamento de Ações Programáticas e Estratégicas e Política de Humanização, Secretaria de Atenção

à Saúde, Ministério da Saúde. Brasília, DF, Brasil.serafimsantos@ terra.com.br 


\section{Introdução}

Os cursos de formação da Política Nacional de Humanização/SUS (PNH) têm como proposta formar profissionais de saúde que possam desenvolver a capacidade de análise do trabalho, de fomento e de consolidação de mudanças na gestão e nos modos de atenção à saúde ${ }^{1}$. Assim o processo de formação sustenta-se em práticas concretas de intervenção, cujos referenciais da PNH passam a ser operacionalizados no sentido de produzir práticas coletivas entre e com os diferentes atores do Sistema Único de Saúde: usuários, trabalhadores e gestores². São processos onde a formação não se separa da intervenção, do mesmo modo que as situações concretas de trabalho são espaços privilegiados de formação.

Nesse sentido, os cursos agregam em seu desenvolvimento, bem como em seus efeitos esperados, a dimensão de apoio institucional ${ }^{3-6}$. O apoio é uma função estreitamente relacionada ao desafio de operar mudanças nos serviços de saúde no rumo da cogestão. Ao atravessar o processo de trabalho dos coletivos, os apoiadores institucionais assumem uma dupla função: qualificar as ofertas clínicas e de saúde pública, assim como ampliar o grau de grupalidade dos coletivos. O trabalho de um apoiador é servir de apoio para processos de mudança nas organizações, misturando e articulando conceitos e tecnologias advindas da análise institucional e da gestão, entre outros. Em síntese a tarefa primordial do apoio seria ofertar suporte ao movimento de mudança deflagrado por coletivos, buscando fortalecê-los. E isso também se configura como objetivo ampliado dos cursos da PNH.

Neste texto se apresenta uma experiência de formação na $\mathrm{PNH}$, partindo desses referenciais e tendo como foco o fomento de redes. Tal foco se desdobra na discussão de corresponsabilidade dos atores e instâncias envolvidas nos processos de produção de saúde, como caminho para minimizar as fragmentações neles observadas.

Assim a ideia da descentralização do SUS passa a ser potencializada na dimensão de criação ou invenção permanente de redes na forma de territórios vivos, com a noção de responsabilidade sanitária também potencializada no campo da micropolítica e relações entre os sujeitos. Assim, espera-se que (novas) práticas de saúde possam ser produzidas, simultaneamente ao alcance de outros níveis de autonomia dos sujeitos.

Ao demarcar as premissas do curso aqui descrito, propomos uma diretriz político-metodológica que tem como base a seguinte articulação: (i) tomar a rede SUS como o espaço concreto das relações de trabalho e produção de subjetividade, induzindo-se a pensá-la em sua "capacidade autônoma" de reinvenção permanente, (ii) compreender o apoio institucional como estratégia de se entremear nos movimentos de tal rede, potencializando a sua condição de autonomia e (iii) conceber o processo formativo como estratégia de colocar em análise os modos de trabalho nessa rede, induzindo ou fortalecendo o potencial dos trabalhadores para agirem como apoiadores institucionais. Este então é o produto-efeito que aqui indicamos para os objetivos ampliados dessa atividade formativa na $\mathrm{PNH}$. Tal articulação é o foco do curso apresentado neste artigo.

\section{A concepção do processo formativo no âmbito de uma rede hospitalar}

Seguindo as bases metodológicas indicadas, foi organizado e desenvolvido um curso numa rede hospitalar do SUS, que foi construído coletivamente a partir de uma instância estratégica de discussão metodológica e de decisão. Essa instância é nomeada Câmara Técnica de Humanização dos Hospitais do Rio de Janeiro (CTH-RJ), aqui cabendo breve descrição desse espaço institucional.

A constituição de uma Câmara Técnica de Humanização (CTH-RJ) foi uma iniciativa conjunta da PNH e da Diretoria de Gestão Hospitalar (DGH)/MS responsável pela gestão da rede de hospitais federais no Rio de Janeiro. Foi constituída em outubro de 2005, compondo-se com representantes de cerca de vinte unidades hospitalares, incluindo os próprios federais (aí incluídos os grandes institutos especializados) e os universitários. Esses serviços são centros de excelência e referências locais, estaduais e nacionais do SUS. O principal objetivo da CTH foi o de aproximação, conhecimento e estímulo ao intercâmbio das experiências de humanização existentes nesses serviços, propondo-se 
ampliação e acompanhamento coletivo das ações. Como resultado do primeiro encontro de trabalho, houve a construção de um mapa das iniciativas existentes e a instalação da $\mathrm{CTH}$, estabelecendo um cronograma sistemático de reuniões? ${ }^{7}$.

Ao longo de sua existência, a CTH tem se consolidado como dispositivo de produção de rede e de cogestão. Toma como ponto de partida as experiências concretas dos serviços, que são trazidas ao debate coletivo, sendo problematizadas à luz de um olhar analítico-avaliativo referenciado nos princípios, diretrizes e dispositivos da $\mathrm{PNH}$.

Além disso, funcionando na lógica do apoio institucional, houve uma preocupação dos coordenadores da CTH em fomentar a construção da grupalidade, oferecendo suporte aos trabalhadores, fortalecendo sua condição de sujeitos comprometidos com a mudança nos modos de gerir o trabalho em suas unidades ${ }^{7}$.

$\mathrm{Na}$ dimensão de tecedura de redes, um importante papel da coordenação e dos consultores da PNH é o de possibilitar e apoiar conexões intra e entre os serviços, relacionar experiências. Como resultado dessas intervenções, observa-se extenso movimento de trocas, incluindo ações de intercâmbio e participações em atividades gerais de todos os serviços.

Em 2008, a CTH construiu duas propostas inovadoras no sentido de fortalecer o movimento de fomento às redes. Por um lado, propôs o seu funcionamento como uma Câmara Técnica itinerante, onde as reuniões pudessem ocorrer a cada mês numa das unidades e se pudesse, assim, aprofundar ou atualizar o conhecimento da realidade dos serviços em lócus, contando com a participação ampliada de novos integrantes: os trabalhadores e gestores das unidades que estariam sediando o encontro. Por outro lado, propôs, em acordo com a Política Nacional de Humanização, a oferta de um curso para profissionais inseridos naquela rede hospitalar, com o objetivo principal de fomentar redes, ampliando o alcance e a formação de trabalhadores dos hospitais.

O curso incluiu-se no planejamento da PNH e CTH-Rio de Janeiro para os anos de 2010 e 2011.

Foi nesse contexto, de consolidação de um espaço institucional articulador de serviços e funcionando na lógica de rede, que emergiu a proposta do curso, a ser desenvolvido em um foco potencializador das experiências em andamento. Em seus eixos de aprofundamento, contemplavamse os dispositivos com os quais a PNH opera na transversalização da atenção-gestão, com ênfase em: acolhimento e acesso; clínica ampliada; classificação de risco; ambiência; organização de redes de cuidado; direitos dos usuários; gestão colegiada; valorização do trabalhador; planejamento, monitoramento e avaliação das ações e do trabalho em saúde.

Em nosso referencial a discussão propriamente do trabalho em saúde assume importância estratégica, considerando que se trata do conceito-base do qual deriva a discussão dos demais conceitos-ferramenta com os quais se trabalha na $\mathrm{PNH}^{8}$. Por isso, a necessidade do aprofundamento em torno dessa categoria conceitual, no modo como é abordada também nos processos formativos.

\section{A constituição de redes solidárias nas práticas em saúde, os processos de formação e o trabalho em saúde}

A Humanização, tomada como política pública para atravessar todas as instâncias do SUS, busca, como efeito de suas práticas, fortalecer os processos de descentralização, isto é, a autonomia da gestão na rede de serviços, de maneira a integrar os processos de trabalho e as relações entre os diferentes profissionais ${ }^{9}$. Para tanto, cabe às equipes prepararem-se para lidar com a dimensão subjetiva das práticas do cotidiano profissional.

O curso, que não é transmissão de conteúdo apenas, buscou contribuir na formação de trabalhadores e coletivos para a construção de um modo de gestão efetivamente participativa que posicionasse lado a lado profissionais, gestores e usuários dos serviços de saúde, colocando em análise processos de trabalho. É importante dizer que não partimos da neutralidade do saber, nem do conhecimento como mediação, mas, sim, como produtor de realidade. O conhecimento não está entre um sujeito que aprende e um mundo a ser descoberto. O conhecimento produz sujeitos e mundos. No fazer/aprender, os próprios trabalhadores percebem-se como produtores de conhecimento. 
Aprende-se a fazer inventando, segundo um processo contínuo de aprendizagens de construção e desconstrução de saberes, valores, concepções. Trata-se de inventar pela prática de tateio, de experimentação, de problematização das formas já dadas ${ }^{10}$.

Buscou-se então nos processos de formação, por meio do curso, a construção de novas relações entre trabalhadores da saúde - atores principais dos processos de trabalho nos diferentes estabelecimentos - e aqueles que, também trabalhadores, portam conhecimentos específicos (seja como professores, apoiadores, colaboradores), de forma a se produzir uma relação dialógica entre todos os atores presentes no cenário do curso e que compõem o cenário da saúde: trabalhadores, gestores/gerentes, usuários, apoiadores institucionais, pesquisadores/estudiosos do campo da saúde. Diálogo desejado entre diferentes saberes e práticas que subsidiam e orientam o trabalho transdisciplinar e em equipes multiprofissionais.

$\mathrm{Na}$ esteira desse processo, trazem-se à tona as diretrizes da Política de Humanização, convergindo na perspectiva da autonomia e protagonismo dos coletivos que constroem a rede SUS e da corresponsabilidade dos sujeitos nas práticas de atenção e de gestão. Tais diretrizes afirmam os diferentes serviços que compõem essa rede como espaços de produção de serviços para os usuários e espaços de afirmação do potencial criador dos sujeitos que neles habitam.

Mas como a temática do trabalho em saúde foi abordada no curso? De que trabalho se trata? Como se coloca o tema processos de trabalho no âmbito das propostas de formação na PNH? Com que referenciais estamos acompanhados quando colocamos como dimensão importante das práticas formativas os processos de trabalho em saúde?

O debate sobre as mudanças que vivemos hoje nas relações de trabalho tem sido o foco privilegiado também no campo da saúde e as práticas de formação no âmbito da PNH não estão alheias a esse debate. Vários trabalhos já apontaram para a discussão sobre o fato de o taylorismo ter deixado de responder às necessidades da indústria ou apenas atualizar-se, sem perder suas características de fundo ${ }^{11-14}$. No caso especial da saúde, a crítica tem sido cada vez mais contundente sobre a taylorização nesse setor de serviços ${ }^{3}$.

Nesse debate observamos com interesse as aproximações que podemos fazer entre as análises do "modelo" de organização e o que se observa nos estabelecimentos de saúde. O curso teve como diretriz, portanto, colocar em diálogo o modo como o trabalho se desenvolve nos serviços e a potência dos coletivos na transformação dos modos instituídos quando o dialogismo se viabiliza nos espaços laborais. Como trabalhar de forma cogestiva conforme indica os princípios do SUS atualizados na PNH?

Com essa diretriz de análise, buscou-se destacar e discutir com os cursistas a importância de conhecer mais de perto o vivido nas situações de trabalho nos estabelecimentos de saúde hoje, seus efeitos "formativos" e avaliar quais as novas relações ou que modalidades de relações existentes fazem frente a essa situação, mesmo que de forma ínfima, ou seja, relações que indicam outros possíveis.

Existe um mundo a ser conhecido nos serviços, um mundo de problemas, de práticas, e foi essa a direção priorizada no curso e na atividade de apoio institucional efetivado nesse processo de formação. Uma estratégia utilizada foi colocar em diálogo as diferentes formas de se trabalhar em saúde e viabilizar a criação de outros modos que pudessem ampliar a força interventiva daqueles trabalhadores em processo de formação, aposta maior da $\mathrm{PNH}$.

Tradicionalmente, e principalmente a partir de Taylor, acredita-se que o trabalho humano pode ser condicionado a um jogo de mecanismos inanimados, ou seja, as máquinas e o trabalho morto conduziriam o processo de produção tornando o indivíduo totalmente dependente das heterodeterminações, reguladas de acordo com as exigências do alto rendimento produtivo. A Política Nacional de Humanização não caminha nessa direção. Ao longo do processo formativo essa questão retornava como indagação: como a função apoio pode contribuir na afirmação de um trabalho protagonizado pelos trabalhadores? Afinal, como já indicamos, uma das diretrizes da PNH é recusar a concepção segundo a qual o trabalhador é concebido como um executor neutro de prescrições matematizadas e cronometradas, sob o jugo das quais ele não poderia escolher nem a qualidade nem a intensidade, nem a frequência da atividade a ser realizada. É, em análise, que se rompe com a perspectiva taylorista, segundo a qual o trabalhador eficiente é aquele que obedece às normas e à lógica da alta produtividade, na qual a racionalidade técnica figura como protagonista e, então, 
opõe-se subjetividade e trabalho. O trabalhar incluído no registro do mecânico, da "pura execução", do assujeitamento, não poderia se expressar a não ser fora dele. O trabalhador também faz "uso de si por si" nos processos de trabalho ${ }^{12}$.

Hodiernamente essa herança gestionária, revestida com outras roupagens sob o signo do capital, essa maneira de controlar o processo de produção, ganha estatuto e força, podendo agir silenciosamente nos corpos dos trabalhadores, em sua condição estética, no campo das emoções, afetos, desejos e toda a sua história. Tudo que foge ou escapa aos modos de subjetivação capitalística, tudo aquilo que não é "fiel" ou é diferente das metas se torna elemento de repúdio e ganha rótulo de anomalia. A "maquínica" do trabalho busca engolir os corpos, anular suas diferenças, transmutandoos, assim, em massas uniformes, sem rosto e sem nome; apenas força de trabalho a ser dirigida por uma vontade exterior, alienante e arbitrária.

Não obstante, afirmam, os trabalhadores não são passivos às estratégias de dominação, nem esse processo se desenrola sem lutas. Trabalhar, sob o prisma do "uso", é colocar em jogo limites e capacidades na atividade, portanto, é colocar-se à prova; é, de certa maneira, correr o risco, já que as normas não antecipam tudo. O trabalho não pode ser realizado de antemão, por isso trabalhar é se encontrar em situação de prova, de prova de existência na qualidade de "si" no trabalho.

As questões trazidas por esses autores alimentavam as conversas e controvérsias ao longo do curso. Afirmava-se a atividade de trabalho em saúde como uma espécie de "dramática", uma vez que, além dos "usos de si pelos outros"12, o trabalho é sempre singularização e ressingularização por usos de si-mesmo. Por outro lado, reconhecemos, ao lado de $\mathrm{Clot}^{11}$, que o trabalhador não age de forma individual, ninguém trabalha sozinho mesmo quando se tem essa impressão, porque os outros estão lá por meio da preparação do trabalho, da prescrição, da avaliação, da conformação do espaço físico, dos materiais e instrumentos. Relacionar-se com o "outro", de alguma maneira, é condição sine qua non da atividade de trabalho. E esse é um critério fundamental para que se efetive um trabalho cogestivo.

Assim, íamos constituindo a base de sustentação do apoio exercitado no referido curso de formação com os trabalhadores dos hospitais do Rio de Janeiro: pensar o trabalho como atividade, como uso e não como execução, de forma que a equipe de trabalho é considerada como um nó da rede de saúde. Para que os princípios do SUS sejam afirmados é imprescindível a construção de redes de cooperação que acompanhem a vida humana na sua mais ampla diversidade. Ao propor a discussão de "redes de produção em saúde"10, a PNH registra que muitas são as experiências onde o "compartilhar" e o "pensar conjuntamente" produzem um ambiente de trabalho democrático e propiciador de processos de trabalho pautados na produção de criação em detrimento da produção de repetição. Nosso ponto de partida é, portanto, que há uma indissociabilidade entre o cuidado em saúde e o cuidado com as relações entre trabalhadores, usuários e os gestores/diretores/coordenadores/gerentes/secretários, de forma a tecer uma rede viva que sustenta nossas ações.

Então, o esforço individual é substituído ou ampliado por processos de trabalho coletivos, no que se persegue a produção de um comum, a construção de processos de trabalho como um coletivo-rede. Formar rede-equipe não é produzir um sistema comunicacional técnico-burocrático, verticalizado, mas um sistema de múltiplas conexões, em várias direções, que amplia nossa capacidade de criar e transformar os processos de trabalho, aumentando espaços de negociação entre todos que participam de uma equipe de trabalho e, também, entre as diferentes equipes de trabalho de um serviço ${ }^{10}$.

Por conseguinte, de um processo fragmentado, buscamos fazer emergir sujeitos coletivos (capazes de formar rede-equipe), alterando o rumo de seu isolamento, marcado pela quebra das alianças. $O$ trabalho em equipe, não é, pois, realidade definida a priori, mas é algo que se constrói no cotidiano.

Rede-equipe se define por um modo de trabalhar dialógico, não se reduz a uma reunião de indivíduos ou de categorias profissionais:

É a reticularidade, ou seja, esse funcionar em rede, que nos permite escapar ao que está cristalizado nos mundos do trabalho e que tenta dificultar ou restringir os processos de criação dos trabalhadores da saúde..$^{10}$ (p. 196) 
Um coletivo-rede nos processos de trabalho viabiliza um trabalhar que não se limita ao que está prescrito na organização do trabalho, mas afirma a dimensão agir-criar próprio dos humanos em atividade laboral. Um coletivo-rede, que não é o mesmo que um conjunto de trabalhadores, constituído por categorias socioprofissionais, mas age enredado nas normas que dizem de um patrimônio que os trabalhadores da saúde construíram, e continuam construindo coletivamente, ao longo da história. Eles se constituem a cada situação experimentada, não preexistem a elas. Uma equipe-rede não se constitui sobre um coletivo predefinido, seus contornos variam em função do conteúdo e do ritmo da atividade de trabalho, o que existe a priori é uma indeterminação ${ }^{10}$. Equiperede, que acessa um plano comum, mantém a diferença e a diferenciação e, mais do que manter as diferenças entre trabalhadores, forja e força que eles se diferenciem, de forma a entrar em contato com o que é diferente, e se diferencia neles e entre eles. Algo se passa na fronteira entre um trabalhador e outro.

Ainda cabe lembrar que essa equipe-rede traz o desafio de se constituir numa dimensão transdisciplinar, uma vez que as fronteiras disciplinares são instáveis, móveis. É a dimensão transdisciplinar que dá à equipe sua dimensão reticular. Novas experiências são criadas nessas fronteiras móveis entre os trabalhadores. Outros modos de trabalhar viabilizam-se na constituição de uma equipe-rede-transdisciplinar, tornando as fronteiras disciplinares instáveis, desestabilizando os campos de saberes disciplinares, privilegiando-se a relação entre os diferentes trabalhadores (gerentes, coordenadores, enfermeiros, médicos, etc.), o que quer dizer privilegiar as redes.

Essa perspectiva das equipes-redes é privilegiada pela $\mathrm{PNH}$ no seu desafio de reafirmar os princípios do SUS e potencializar sua operacionalidade na ótica da descentralização, da autonomia e da (cor) responsabilização sanitária.

Aqui, portanto, o trabalho não é apenas o que está definido para ser executado pelos diferentes profissionais, mas, também e, principalmente, o que efetivamente se realiza nas situações concretas de trabalho. Inclui, portanto, o esforço que se despende no cotidiano laboral para o trabalhador dar conta dos acordos e pactos realizados com o gestor e com os companheiros de trabalho, em função do que demandam os usuários.

Interessa-nos o trabalho como um objeto tecido a cada situação, construído e reconstruído na atividade. Mais do que o trabalho, interessa-nos o trabalhar, a atividade com seu movimento e singularidade. Falar do trabalho como atividade é falar, no nosso entendimento, de produção de subjetividade, entendendo subjetividade também como processo, de caráter tanto coletivo quanto singular. Foi com essa diretriz que foram construídas as bases para o processo formativo, enfatizando a lógica de rede.

No tópico seguinte indicamos as estratégias desencadeadas para materializar essa discussão. Antes, reafirmamos aqui as grandes questões norteadoras: como produzir saúde e produzir sujeitos alinhados com os princípios de descentralização do SUS? Quais estratégias foram utilizadas na condução/ apoio ao curso desenvolvido com profissionais da saúde? Que dispositivos foram criados no curso de formação para trabalhadores dos hospitais do RJ para que os processos de trabalho em saúde fossem analisados viabilizando modos de trabalhar que aquecessem redes?

\section{A experiência do curso: tecendo redes na rede hospitalar do Rio de Janeiro}

\section{Primeira etapa - a construção e desenvolvimento do processo de formação na Câmara Técnica de Humanização: formação de formadores}

O curso foi concebido nas reuniões mensais da CTH-RJ, durante os anos de 2009 e 2010, e seguiu o método da inclusão trabalhado na $\mathrm{PNH}^{15}$, isto é, partindo das experiências concretas nos serviços (inclusão dos contextos e seus desafios) e da incorporação dos trabalhadores em sua construção (inclusão dos sujeitos).

Ao longo de 2010, foi organizada uma agenda da CTH-RJ voltada para a formação de seus componentes como grupo que se constituiria com a função de "formadores" (facilitadores) do curso. 
Como se tratava de trabalhadores que já estavam envolvidos com o debate sobre Humanização, entendeu-se que eles deveriam compor o colegiado gestor do curso, assumir o papel de suporte nas atividades do processo de formação, acompanhar as atividades de dispersão em suas respectivas unidades e também no desenvolvimento dos planos de intervenção (parte dos produtos esperados).

Essa primeira etapa, nomeada de "Formação de Formadores" no próprio espaço da CTH-RJ, abarcou o período de março a junho de 2010, envolvendo aproximadamente vinte formadores (um formador/trabalhador por unidade), com cinco encontros temáticos presenciais, coordenados pelos consultores da Política Nacional de Humanização do Ministério da Saúde. O cronograma e os temas abordados foram: "Princípios e diretrizes da Política Nacional de Humanização" (três encontros), "Concepção de curso e de apoiadores institucionais" (um encontro), "Concepção de intervenção e de eixos de acompanhamento avaliativo (um encontro). Além desses encontros, outros foram derivados para avaliação e construção propriamente da etapa que seria realizada com os trabalhadores.

No primeiro encontro dessa primeira etapa, foram retomadas e reafirmadas as diretrizes da Política Nacional de Humanização, entendida como uma política que coloca em análise processos de trabalho e propõe transformação nas práticas de atenção e gestão em saúde, articulando-a ao processo de formação proposto. O objetivo dessa apresentação foi, então, destacar aspectos dessa política que seriam priorizadas no curso: a metodologia inclusiva, valorizada pela $\mathrm{PNH}$, e ofertas na forma de dispositivos, que poderiam contribuir para reorganização das práticas.

No debate os trabalhadores trouxeram os limites e as possibilidades de cogestão em seus lugares de trabalho. Refletiam sobre a possibilidade de sair da condição de "queixa" para a condição de análise das relações de trabalho e de transformação das ações, de forma que o processo de formação pudesse se tornar ferramenta potente para tanto. No enfrentamento desses desafios, destacava-se a importância de se considerar a atividade de trabalho, que ocorre nessa tensão dos usos de si "por si" e "pelos outros", implicando que o trabalhador convoque e efetue reconvocações para realizar o trabalho. Construir processos cogestivos de trabalho é por em jogo recursos e capacidades, largamente mais complexos do que aqueles explicitados, do que aqueles que a tarefa cotidiana solicita. Há, desse modo, a aplicação de um capital pessoal e coletivo, pelos quais Schwartz ${ }^{14}$ justifica a opção pelo termo "uso" - nunca só execução, mas "uso".

No curso da conversa destacava-se, então, que a análise das relações de trabalho em saúde implica considerar uma dinâmica que não é própria ao indivíduo, mas que o constrói por isso. Escolhendo esse ou aquele procedimento ou modalidade de ação, escolhe-se, de certa maneira, a relação que se quer com o outro e com o mundo no qual se deseja viver.

Diante disso, a construção de "si-mesmo" ocorre por meio da relação com o outro, também dos usos que os outros fazem nesse "uso de si"; dito de outro modo: o uso de si pelos outros. Essa é a direção de um trabalho efetivamente gerido de forma compartilhada. Toda atividade, todo trabalho é sempre uso, este "uso de si" é marcado pela dualidade às vezes simples e ao mesmo tempo muito complexa, que é o uso de si "por si" e "pelos outros". É devido a essa ambivalência do uso que todo trabalho é problemático - problemático e frágil - e comporta uma dramática ${ }^{12,14}$.

Assim sendo, os desafios na construção de processos de trabalho cogestivos implicam debate de normas, tentativa de desanonimar o meio no enfrentamento das suas infidelidades, e implicam permanentemente o risco de essa tentativa fracassar. Por isso, trabalhar é se arriscar, mas com o cuidado para que o risco não se transforme em perigo, em sofrimento paralisante e, consequentemente, impeça a dinâmica e a tensão entre os usos de si "por si" e pelos outros, condições de possibilidades pelas quais se podem criar novas normas, novas formas de vida, novas maneiras de existir no trabalho e instituir modos não verticalizados e autoritários de trabalhar. Tratase de um processo que deve ser expressão, sobretudo, de "uma vida", e não pode ser reduzido simplesmente a um valor monetário, nem tampouco ao idêntico, ao mecânico, ao biológico. Esses seriam aspectos que, para trazer Canguilhem ${ }^{16}$ à conversa, descaracterizariam a essência do ser vivente e tornariam a vida "invivível".

Nos dois encontros seguintes tematizamos as diretrizes da Política Nacional de Humanização, a partir das experiências concretas dos trabalhadores nas suas unidades. Cinco hospitais apresentaram ações que vêm desenvolvendo e que estão relacionadas às diretrizes de acolhimento, ambiência, clínica 
ampliada, direito dos usuários e valorização do trabalho e do trabalhador. Essa metodologia possibilitou que os participantes assumissem o papel de protagonismo, podendo falar sobre as suas realidades de trabalho, buscando coletivamente construir soluções inovadoras para os problemas cotidianos relacionados à gestão e a organização da rede de saúde.

No encontro sobre a concepção de curso e de apoio institucional, a apresentação e o debate circularam em torno da noção-chave de "apoio institucional", entendido como a função de ofertar suporte ao movimento de mudança deflagrado por coletivos, buscando fortalecê-los no próprio exercício da produção de novos sujeitos em processos de mudança. O objeto de trabalho do apoiador é, sobretudo, o processo de trabalho de coletivos que se organizam para produzir, em nosso caso, saúde $^{5}$. A partir dessas noções, os trabalhadores trouxeram o desafio de formar um coletivo para colocar em análise os processos de trabalho nas unidades. Após o momento de exposição das dificuldades e desafios, alguns formadores trouxeram experiências desenvolvidas por intermédio das rodas de conversa nas unidades hospitalares.

O último encontro foi reservado para abordar a construção de planos de intervenção. Debateu-se sobre a noção da PNH de cursos direcionados para "formação-intervenção", ou seja, formação baseada em práticas concretas de intervenção dos trabalhadores nos processos de trabalho em saúde. Foram oferecidos instrumentais metodológicos para o desenvolvimento e acompanhamento avaliativo dos planos de intervenção nas unidades².

Ao fim dessa etapa inicial de formação de formadores na CTH-RJ, realizamos alguns encontros para avaliação e planejamento das próximas etapas do processo de formação, incluindo os formadores trabalhadores, garantindo assim a gestão compartilhada do processo de formação entre a $\mathrm{PNH} / \mathrm{MS}$ e os membros da CTH.

\section{Etapa intermediária - ampliando a rede na Câmara Técnica de Humanização: encontros preparatórios com os trabalhadores da rede hospitalar do Rio de Janeiro}

Um dos desdobramentos das avaliações realizadas na etapa de formação dos formadores no âmbito da CTH-RJ foi que os trabalhadores selecionados para participarem do curso precisavam ser incluídos naquele estágio de sua construção. Muitos formadores já vinham sensibilizando seus coletivos para os debates da Política Nacional de Humanização, outros já se encontravam com um coletivo fortalecido e que já vinha pensando e/ou planejando ações no âmbito da PNH.

Embora as unidades se diferenciassem em termos de um maior ou menor amadurecimento em relação aos debates da $\mathrm{PNH}$, os formadores, participantes da $\mathrm{CTH}$, foram unânimes quanto à decisão de que o processo iniciado com a formação de formadores (concluindo-se ao final do primeiro semestre de 2010) não deveria ser interrompido e sim emendado no início do curso propriamente com os trabalhadores.

O Colegiado Gestor do Curso, que envolvia os consultores da PNH e os formadores das unidades, estruturou o desenho dos encontros, incluindo os temas e a metodologia de abordagem, utilizando-se especialmente o dispositivo das rodas ${ }^{3}$.

Os três primeiros encontros enfocavam os temas estruturantes da $\mathrm{PNH}$, o apoio institucional e a concepção de curso na PNH e para o fortalecimento do SUS.

No primeiro encontro, optou-se em fazer uma atividade em que os trabalhadores das diferentes unidades pudessem se conhecer e conversar sobre os temas propostos. Assim, por meio de uma dinâmica nomeada de "Café PNH", os trabalhadores puderam conversar sobre os seus entendimentos do que era a $\mathrm{PNH}$, a noção de apoio institucional e as expectativas em relação ao curso. Essa atividade inicial foi muito bem recebida pelos trabalhadores, pois relataram que puderam "se colocar em rede" com as outras unidades, ouvir e trocar experiências em relação à função de apoio institucional e as ações que envolviam a PNH nos serviços. Assim, todos experimentaram a ampliação da rede constituída na Câmara Técnica de Humanização e a potência que se abria para a formação de uma "rede quente".

Nos encontros seguintes, o tema "apoio institucional" foi apresentado. Após sua exposição, os grupos divididos em unidades foram convidados a pensar quem poderia encarnar a função de 
apoiador, de que lugar e do que se ocuparia prioritariamente". Nessa atividade os grupos puderam se reunir e pensar as estratégias de intervenção nas unidades. As falas foram heterogêneas. Alguns serviços já tinham trabalhadores que vinham ocupando a função de apoiadores institucionais, analisando coletivamente seus processos de trabalho e pensando modos de transformação nas práticas de produção de saúde. Outros ainda estavam se deparando com a ideia de apoio institucional e começando um processo de construção de um coletivo em suas unidades.

Esses encontros findaram com uma avaliação positiva dos formadores, sobretudo em dois aspectos: a formação de redes entre as unidades, com a possibilidade de interação e troca de experiências e a tematização da PNH para dentro das unidades de maneira mais ampla e abrangendo mais atores.

\section{Segunda etapa - a formação ampliada de apoiadores institucionais}

O curso voltado para duzentos trabalhadores da rede hospitalar ligada à CTH-RJ teve início, em março de 2011, e foi dividido em cinco módulos presenciais de dois dias cada, com encontros mensais. Os temas abordados e sua distribuição foram: Módulo 1 - A PNH, seu método e perspectivas atuais; Análise de Contexto das situações locais, com debate e levantamento de desafios das unidades. Módulo 2 - Acolhimento e classificação de risco; Ambiência. Módulo 3 - Direito dos usuários e Cogestão; Saúde e Trabalho. Módulo 4 - Clínica ampliada; Redes de produção de saúde. Módulo 5 Planejamento, monitoramento e avaliação; Planos de intervenção.

Os encontros tinham a seguinte dinâmica: na parte da manhã era apresentado o tema do dia por meio de uma exposição dialogada conduzida por um consultor da Política Nacional de Humanização. $\mathrm{Na}$ parte da tarde os trabalhadores se reuniam em grupos para discutir e refletir sobre a inserção daquele tema (uma diretriz ou dispositivo da política) em suas respectivas unidades. A cada encontro presencial eram pactuadas atividades de dispersão a serem realizadas pelos participantes em seus respectivos serviços. Essas estratégias metodológicas serviram como pontos de partida para disparar a articulação da rede.

As atividades a serem realizadas pelos participantes em suas unidades de saúde eram propostas pelos consultores, acordadas com os trabalhadores, e não obedeciam a uma estrutura rígida. Os grupos puderam se encontrar de acordo com a disponibilidade dos seus membros.

O curso iniciou-se com uma proposição de mapear os problemas observados pelos participantes em seus processos de trabalho. Aqui sintetizamos as principais questões levantadas, demonstrando a amplitude de sua abrangência. Os trabalhadores apontaram precisamente aspectos indicativos da fragmentação referida no início deste texto, assim reafirmando-se tais questões como desafios de intervenção à luz da PNH. E também foram recorrentes os problemas gerais que têm aparecido em outras avaliações e em reclamações cotidianas dos trabalhadores da saúde. Emergiram então: a precariedade na estrutura física dos serviços, a fragilidade de vínculo empregatício dos trabalhadores, os baixos salários, a mudança constante na gestão, a falta de comunicação entre os profissionais, o desconhecimento da PNH pelos trabalhadores e gestores, o não comprometimento da gestão com as mudanças necessárias nos serviços de saúde e a inexistência de uma rede de saúde.

A dinâmica de discussão e as atividades propostas nos encontros presenciais e de dispersão tinham como objetivo estimular os trabalhadores a criarem estratégias de intervenção diante dos desafios colocados nos serviços e rede de saúde. Pretendíamos que o grupo assumisse seu protagonismo e sua corresponsabilização em seus processos de trabalho.

Essas atividades estiveram relacionadas aos temas mencionados anteriormente, possibilitando o debate do cotidiano de trabalho no SUS, os desafios vivenciados no dia a dia e a criação de estratégias coletivas para a superação dessas dificuldades - lembrando que tais criações ou invenções sempre existem como reações vivas que se operam no trabalho e que podem ser potencializadas em algumas direções, sem desconsiderar que também apresentam limitações circunstanciais.

A realização das atividades e desse debate nos encontros presenciais materializava o método de inclusão da PNH, ou seja, trabalhar com as práticas concretas dos trabalhadores, incluir os conflitos e as relações de poder, e dialogar criticamente com os diversos tipos de fatores interferentes.

De modo mais específico, as falas dos trabalhadores deram visibilidade à situação em que se 
encontravam os serviços em relação às diretrizes da PNH. Observou-se que a incorporação dos referenciais dessa Política ainda é um desafio para a maioria dos serviços. Muitos relatam que os gestores não têm interesse em implementar as diretrizes e dispositivos de reorganização da atenção e gestão, outros encontram dificuldades na resistência dos profissionais, na não adesão de algumas categorias profissionais aos processos de mudança, no funcionamento verticalizado da gestão, na ambiência inadequada e tudo isso ajudando a fragilizar as condições de trabalho e a própria saúde do trabalhador.

$\mathrm{Na}$ espiral de escuta e problematização de dificuldades, mas também de experiências exitosas indo e vindo guiados pela metodologia da inclusão e do apoio -, observou-se que embora a PNH seja ainda um grande desafio para a realidade dos serviços, há coletivos mobilizados e com iniciativas a serem compartilhadas em sua potência.

Muitos serviços têm criado formas originais de acolhimento ao usuário, de garantia e ampliação dos seus direitos, como o acompanhante junto aos procedimentos e internações, a extensão de horários de visitas para os usuários internados (visita aberta), além das iniciativas de fortalecimento da gestão participativa, como a criação de espaços coletivos de decisão e de análise dos processos de trabalho.

No movimento de discussão dessas e outras situações, possibilitou-se o resgate e o compartilhamento das experiências vivenciadas e a análise das implicações dos sujeitos em tais experiências. O curso foi constituindo-se, portanto, como um espaço de criação de redes entre os trabalhadores e de comunicação entre os diferentes serviços. Desvelava-se assim a concepção de que trabalhar é gerir. É gerir junto com os outros.

Um dos maiores indicadores do que estamos afirmando foi a criação de um comitê com a elaboração de uma proposta de construção de rede de atendimentos entre as unidades hospitalares participantes do curso.

No último módulo do curso, os participantes foram convidados a construir um planejamento de intervenção para seus serviços, que passariam a ser acompanhados nas unidades pelos formadores do curso, além de tematizados e supervisionados no âmbito da CTH.

\section{Concluindo: aprendizado que prossegue...}

As avaliações feitas pelos participantes desse processo de formação possibilitaram reafirmar o curso como oportunidade de problematização da experiência vivenciada, uma vez que se privilegiou o seu compartilhamento.

Embora o curso tenha exercido uma função de grupalidade, produzindo o aquecimento de redes entre os trabalhadores nos seus serviços e no sistema local de saúde, entendemos que não se trata de um processo finalizado, pois as situações concretas de trabalho são espaços privilegiados de formação. Estamos sempre num certo aprendizado, numa certa transformação, em meio a intervenções recíprocas. É, principalmente, em atividade que um trabalhador da saúde se forma. As práticas formativas que assinamos nesse curso indicam total incompatibilidade com uma noção invariante de sujeito e de processos de trabalho. Formação é entendida como produção de subjetividade como "estilismo de si" em sua natureza coletiva, pensada como vetor de subjetivação e, portanto, indissociável de modos de viver que implica desafios no mundo.

No curso buscou-se dar passagem aos gestos que, marcados por estratégias de invenção, aliam-se e comprometem-se com os processos de produção da diferenciação. Trata-se de afirmar que a prática formativa se faz no encontro com a alteridade, com o outro em sua diferença, destruindo evidências e universalidades e recusando configurações totalizadoras que não favorecem a expressão do processo vital. Não é um processo finalizado, portanto, uma vez que não se reduz à transmissão de conteúdos, mas é criação de estratégias para encontrar indícios que possam nos fazer mudar de caminho, rever estratégias e prosseguir no trabalho de construção de práticas não aprisionadas sob a ótica da produção de profissionais que valorizam certo tecnicismo estéril. Tais processos formativos fomentam a multiplicidade, ao invés de esmagá-la, exercitando o “[...] corpo e o pensamento a vivenciar seus 
limites e ultrapassá-los. Formação como pensamento afirmativo da vida, cruel e contrário a uma pedagogia piedosa e vingativa"17 (p. 18).

Tomar a formação nessa direção é considerá-la como instituição que produz modos de subjetivação, objetos-saberes, prática que pode provocar movimentos, estabilizações e desestabilizações, naturalizações e produção de problemas que interrogam esses modos naturalizados de trabalhar em saúde, logo, faz-se no jogo infinito de produção de outros modos de trabalhar. Formação-criação é experimentação constante, maneiras diferentes de fazer, pois fazer a tarefa de forma mecânica é impossível e "invivível" ${ }^{13}$. Formação é aprendizagem permanente, questiona as prescrições e constrói outros modos de trabalhar para dar conta de situações novas e imprevisíveis. É processo que acompanha a vida na variação que the é própria.

\section{Colaboradores}

Os autores trabalharam juntos em todas as etapas de produção do manuscrito.

\section{Referências}

1. Pavan C, Gonçalves L, Matias MC, Paulon S. Documento orientador da política de formação da PNH. Cad Humanizasus. 2010; (1): 74-93.

2. Santos-Filho SB. Avaliação e Humanização em saúde: aproximações metodológicas. Ijuí: Ed. Unijuí; 2009.

3. Campos GWS. Um método para análise e co-gestão de coletivos. São Paulo: Hucitec; 2000.

4. Pashe $D$, Passos E. Inclusão como método de apoio para produção de mudanças na saúde: aposta da Política de Humanização da Saúde. Saude Debate. 2010; 34(86):423-32.

5. Oliveira GN. Devir apoiador: uma cartografia da função apoio [tese]. Campinas (SP): Universidade Estadual de Campinas; 2011.

6. Vasconcelos $M$, Morschel A. O apoio institucional e a produção de redes: do desassossego dos mapas vigentes na Saúde Coletiva. Interface (Botucatu). 2009; 13(1):729-38.

7. Santos-Filho S, Benevides R. Câmara Técnica de Humanização como dispositivo de co-gestão: experimentando o conceito de rede. In: Santos-Filho S, Barros MEB, organizadores. Trabalhadores da Saúde: muito prazer! Protagonismo dos trabalhadores na gestão do trabalho em Saúde. Ijuí: Unijuí; 2007. p. 203-32.

8. Santos-Filho S, Barros MEB, Gomes R. Alguns conceitos articuladores na discussão do processo de trabalho em saúde. In: Avila A, Machado J, organizadores. Panorama da saúde dos trabalhadores da saúde. Belo Horizonte: UFMG; 2012. p. 28-65.

9. Benevides R, Passos E. A Humanização como dimensão pública das políticas de saúde. Cienc Saude Colet. 2005; 10(3):561-71.

10. Ministério da Saúde. Política Nacional de Humanização. Redes de produção de saúde. Brasília (DF): MS; 2009.

11. Clot Y. A função psicológica do trabalho. Petrópolis: Vozes; 2006.

12. Schwartz Y. Trabalho e uso de si. Pro-posições. 2000; 5(32):p. 34-50. 
13. Schwartz Y. Disciplina epistêmica, disciplina ergológica: paidéia e politéia. Pro-Posições. 2002; 1(37):75-98.

14. Schwartz Y. Trabalho e gestão: níveis, critérios, instâncias. In: Figueiredo $M$, Brito J, Alvarez D, organizadores. Labirintos do trabalho. Rio de Janeiro: DP\&A; 2004. p. 23-33.

15. Ministério da Saúde. Política Nacional de Humanização (PNH). HumanizaSUS: documento base para gestores e trabalhadores do SUS. Brasília (DF): MS; 2006.

16. Canguilhem G. O normal e o patológico. Rio de Janeiro: Forense Universitária; 2000.

17. Fuganti LA. Saúde, desejo e pensamento. In: Lancetti A, organizador. Saúde e loucura. São Paulo: Hucitec; 1990. v. 2, p. 19-82.

Roza MMR, Barros MEB, Guedes CR, Santos Filho SB. La experiencia de un proceso de formación articulando la humanización y el apoyo institucional en el trabajo en salud. Interface (Botucatu). 2014; 18 Supl 1:1041-52.

El texto presenta una experiencia de formación en la Humanización con referencias de apoyo institucional. En la formación se propusieron directrices político-metodológicas: (i) tomar la red del Sistema Brasileño de Saúde (SUS) como el espacio concreto de las relaciones de trabajo y producción de subjetividades, induciéndose a pensarla en su 'capacidad autónoma' (ii) incluyendo el apoyo institucional como estrategia de incluirse en los movimientos de la referida red, potencializando su condición de autonomía y (iii) concibiendo el proceso formativo como estrategia para analizar los modos de trabajo de esa red, induciendo o fortaleciendo el potencial de los trabajadores para actuar como apoyadores institucionales. Este es el producto-efecto que indicamos aquí para agregar en si los objetivos ampliados de esa actividad formativa. El curso ejerció función de formación de grupo, intensificó redes, pero no es un proceso finalizado, puesto que acompaña a la vida en la variación que le es propia.

Palabras clave: Experiencia de formación. Humanización. Apoyo institucional. Trabajo en salud.

Recebido em 24/04/13. Aprovado em 20/09/14. 